RIZZO, A.A.N.; BRAZ, L.T. Características de cultivares de melão rendilhado cultivadas em casa de vegetação. Horticultura Brasileira, Brasília, v. 19, n. 3, p. 237-240, novembro 2.001 .

\title{
Características de cultivares de melão rendilhado cultivadas em casa de vegetação.
}

\author{
Adriana Antonieta N. Rizzo; Leila T. Braz \\ UNESP-FCAV, Depto. de Produção Vegetal, Via de Acesso Prof. Paulo Donato Castellane, s/n, 14.870-000 Jaboticabal-SP. E- \\ mail:drarizzo@fcav.unesp.br
}

\section{RESUMO}

Este trabalho teve como objetivo avaliar cinco cultivares de melão rendilhado com relação as características associadas à produção e qualidade dos frutos e quanto à aparência. $\mathrm{O}$ experimento foi conduzido em casa de vegetação da Faculdade de Ciências Agrárias e Veterinárias-UNESP, Câmpus de Jaboticabal. Utilizou-se o delineamento em blocos ao acaso com 5 tratamentos compostos pelas cultivares Sunrise; Aragon; Halest Best Jumbo; Nero e Bônus n ${ }^{\circ} 2$ e 4 repetições. Foram avaliados o peso médio dos frutos comercializáveis; diâmetro e comprimento médio de frutos; espessura média e coloração do mesocarpo e epicarpo; teor de sólidos solúveis ( $\left.{ }^{\circ} \mathrm{Brix}\right), \mathrm{pH}$ e acidez total. O híbrido Bônus $\mathrm{n}^{\circ} 2$ destacou-se com relação à produção média $/ \mathrm{m}^{2}$, peso médio dos frutos $(\mathrm{Kg})$, espessura da polpa $(\mathrm{cm}) \mathrm{e}^{\circ}$ Brix, características importantes para a produção e comercialização dos frutos de meloeiro, podendo ser indicado para cultivo em casa de vegetação.

Palavras-chave: Cucumis melo var. reticulatus Naud, cultivo protegido, qualidade de frutos, cultivares.

\begin{abstract}
Evaluation of qualitative characteristics of netted melon fruits under greenhouse conditions.

The yield and fruit quality of five cultivars of netted melon were evaluated under greenhouse conditions. The experiment was carried out in Jaboticabal, Brazil. Five cultivars (Sunrise, Aragon, Halest Best Jumbo, Nero and Bônus $\mathrm{n}^{\circ}$ 2) were evaluated in a randomized block design with four replications. Each plot consisted of 3 plants spaced $0.8 \times 1.0 \mathrm{~m}$ apart. The total fruit yield was evaluated; average fruit weight; average longitudinal and transversal fruit diameter; average thickness and flesh and skin color and the qualitative fruit characters, $\%$ total soluble solids, $\mathrm{pH}$ and total acidity. The cultivar Bônus $\mathrm{n}^{\mathrm{o}} 2$ presented the highest fruit yield and average weight, average flesh thickness and total soluble solids.
\end{abstract}

(Aceito para publicação em15 de outubro de 2.001)

$\mathrm{O}$ cultivo de melão rendilhado (Cucumis melo var. reticulatus Naud.) é bastante recente no país. O primeiro registro para fins comerciais foi em 1986, pela Cooperativa Agrícola de Cotia, com sementes importadas do Japão (Rizzo, 1999). Estes melões caracterizam-se por apresentar a superfície do fruto rendilhada, formato redondo a ovalado, peso de 1 a $3 \mathrm{~kg}$, aroma caracte- rístico, polpa bastante doce (Brix ao redor de $10^{\circ}$ ) e coloração que varia entre verde-clara e salmão (Siviero, 1993). Estes tipos de melão apresentam a vantagem da boa cotação comercial e de poderem ser cultivados em pequenas áreas com boa lucratividade. Seu curto ciclo vegetativo é favorecido sob alta luminosidade e temperatura, baixa umidade relativa e boas condições de irri- gação. Recomenda-se o seu cultivo em casa de vegetação, por possibilitar melhor controle das condições ambientais. Ainda, o cultivo em ambiente protegido possibilita semear o melão em várias épocas, proporcionando mais de uma colheita por ano, atingindo altos níveis de produtividade (1.800 - 3.000 frutos/ $1.000 \mathrm{~m}^{2}$ de casa de vegetação) (Brandão Filho \& Vasconcellos, 1998). 
O consumo de melão rendilhado está relacionado ao teor de sólidos solúveis, responsável pelo sabor. Seu aspecto visual diferencia-o dos outros tipos de melão existentes no mercado. Sua qualidade nutricional também tem contribuído favoravelmente para o seu consumo, pois são considerados pouco calóricos e boa fonte de sódio, potássio, vitamina $\mathrm{C} \mathrm{e}$ beta-caroteno (Lester, 1997).

A qualidade em frutos de melão envolve atributos relacionados à precocidade, concentração da produção, aparência (formato, coloração da casca e polpa e presença ou não de rendilhamento), qualidade de polpa e capacidade de armazenamento. A qualidade de polpa é influenciada pelo teor de açúcares, aroma, textura, firmeza e coloração. O teor de açucares é influenciado principalmente pelo conteúdo de sacarose, que é medido pelo total de sólidos solúveis. Comercialmente, frutos com teores de sólidos solúveis entre $12-15 \%$ são considerados de excelente qualidade; teores próximos de $9 \%$ são considerados aceitáveis e, abaixo deste valor, não são comerciáveis (McCreight et al., 1993; Gorgatti Neto et al., 1994).

Segundo Chitarra \& Chitarra (1990), os índices chamados de físicos e quími$\cos$, referentes à transformações morfológicas e fisiológicas pelas quais os frutos passam durante seu desenvolvimento, podem auxiliar na determinação do ponto de maturação destes. Dentre os físicos, pode-se citar o formato dos frutos (incluindo diâmetro longitudinal e transversal) e espessura de polpa e casca. Com relação aos índices químicos, os mais utilizados são $\mathrm{pH}$, acidez titulável e sólidos solúveis totais. Todos são de fácil obtenção, podendo ser indicadores do ponto de colheita, se monitorados durante o desenvolvimento do fruto, pois, próximo deste, o teor de sólidos solúveis aumenta, o $\mathrm{pH}$ varia pouco e a acidez tem uma rápida redução. O fruto ideal deve ter polpa espessa e, consequentemente, uma cavidade interna pequena, pois frutos deste tipo resistem melhor ao transporte e têm maior durabilidade pós-colheita (Costa \& Pinto, 1977).

Neste trabalho, objetivou-se avaliar cinco cultivares de melão rendilhado cultivados em casa de vegetação, com relação à produção, qualidade e aparência dos frutos.

\section{MATERIAL E MÉTODOS}

O experimento foi conduzido em casa de vegetação do Departamento de Produção Vegetal da Faculdade de Ciências Agrárias e Veterinárias, Câmpus de Jaboticabal-SP. Utilizou-se o delineamento em blocos ao acaso com quatro repetições e cinco tratamentos compostos pelas cultivares Sunrise (resistente a oídio e míldio, casca bastante rendilhada, creme e polpa amarelada); Aragon (fruto oval, bastante rendilhado, peso médio entre 1,2 e $1,4 \mathrm{~kg}$, polpa espessa e salmão e casca verde quando maduro); Halest Best Jumbo (fruto ovalalongado, peso médio entre $1,0-1,5 \mathrm{~kg}$, e polpa espessa de cor salmão); Nero (resistente a oídio, fruto arredondado, peso médio entre 1,2 e 1,5 kg, apresenta cavidade interna pequena, polpa salmão, casca bastante rendilhada e verde quando maduro) e Bônus $n^{\circ} 2$ (resistente a oídio, tolerante a nematóides, ciclo médio, fruto arredondado, bastante rendilhado, casca e polpa verde quando maduro, pequena cavidade interna e bom desprendimento das sementes).

Cada parcela foi constituída por uma linha de 3,0 metros de comprimento, com seis plantas. $\mathrm{O}$ espaçamento adotado foi de $1,0 \mathrm{~m}$ entre fileiras e $0,5 \mathrm{~m}$ entre plantas. A semeadura foi realizada no mês de abril de 1996, utilizandose de bandejas de poliestireno expandido com 128 células, preenchidas com substrato para hortaliças (Plantmax). O transplantio para a casa de vegetação foi realizado quando as mudas apresentavam a primeira folha definitiva. As adubações de plantio e cobertura foram realizadas com base em análise de solo, segundo recomendações para a cultura por Raij et al. (1996). O tutoramento das plantas foi feito com fios de ráfia, sendo conduzida uma planta por cova. Foram realizadas desbrotas e amarrios das plantas sempre que necessário. Os demais tratos culturais foram realizados seguindo as indicações para a cultura. Foram deixados três frutos por planta, e a colheita foi iniciada no mês de agosto de 1996, a partir da maturação dos frutos.

Foram coletados dados de produção total de frutos $/ \mathrm{m}^{2}$, peso médio dos fru- tos comercializáveis $(0,3$ a $1 \mathrm{~kg})$; diâmetro médio transversal e longitudinal (cm); espessura média do mesocarpo e epicarpo (cm); coloração do mesocarpo, determinada de acordo com escala de notas (1: verde, 2 : verde claro, 3 : amarelo e 4: laranja); rendilhamento da casca, caracterizado por avaliação visual e teor de sólidos solúveis ( ${ }^{\circ}$ Brix), obtido pela utilização de refratômetro manual; pH e acidez titulável, obtidos pela titulação com $\mathrm{NaOH}$ sobre a diluição de $20 \mathrm{~mL}$ de suco do fruto em $20 \mathrm{~mL}$ de água destilada, usando como indicador fenolftaleina. Foi realizada transformação da acidez titulável segundo Tressler \& Joslyn (1961), utilizando-se do fator de correção (volume de $\mathrm{NaOH}$ titulado $\mathrm{x} 0,32$ ), que proporciona valores em gramas de ácido cítrico/100mL de solução. Com os dados médios de cada característica, realizou-se a análise de variância (ANAVA). Para cada caráter, aplicouse o teste F, quando o valor de F calculado foi significativo, realizou-se comparações entre as médias, pelo teste de Tukey ao nível de 5\% de probabilidade.

\section{RESULTADOS E DISCUSSÃO}

Quanto à produção, a cultivar Bônus $\mathrm{n}^{\circ} 2$, foi a mais produtiva $(12,27 \mathrm{~kg}$ / $\mathrm{m}^{2}$ ), não diferindo apenas de 'Sunrise'. 'Aragon' apresentou a menor média para esta característica, não diferindo de 'Hales Best Jumbo' e 'Nero' (Tabela 1). A produção foi relativamente menor do que o esperado devido à ocorrência do cancro da haste (Didymella bryoniae), que foi prejudicial no final do ciclo da cultura, pois o tratamento realizado com fungicidas não resultou em controle efetivo. As plantas das cultivares 'Aragon' e 'Hales Best Jumbo' demonstraram ser pouco tolerantes ao fungo, o que não ocorreu com as outras cultivares. A ocorrência de oídio (Sphaerotheca fuliginea) também limitou a produção, apesar da constante aplicação de fungicidas recomendados para a cultura.

Considerando-se os padrões de Costa \& Pinto (1977) e Siviero (1993), 'Bônus $n^{\circ} 2$ ' apresentou melhor desempenho em relação às outras cultivares quanto ao peso médio dos frutos, não diferindo apenas de 'Sunrise' (Tabela 1). $\mathrm{O}$ peso médio dos frutos variou entre 
Tabela 1. Médias de seis características em cinco cultivares de melão rendilhado. Jaboticabal, UNESP, 1996.

\begin{tabular}{lccccccc}
\hline \multirow{2}{*}{ Cultivares } & \multicolumn{7}{c}{ Características } \\
\cline { 2 - 8 } & PMFC & PMF* & DML & DMT & EME & EMEP \\
\hline Sunrise & $11,67 \mathrm{ab}$ & $561,75 \mathrm{ab}^{1}$ & $9,57 \mathrm{a}$ & $9,85 \mathrm{ab}$ & $2,37 \mathrm{ab}$ & $2,37 \mathrm{a}$ \\
Aragon & $8,52 \mathrm{c}$ & $353,45 \quad \mathrm{c}$ & $9,04 \mathrm{a}$ & $8,57 \mathrm{~b}$ & 2,03 & $\mathrm{~b}$ & $1,94 \mathrm{a}$ \\
Hales Best Jumbo & $8,32 \mathrm{bc}$ & $362,82 \mathrm{bc}$ & $9,83 \mathrm{a}$ & $8,52 \mathrm{~b}$ & 2,00 & $\mathrm{~b}$ & $1,84 \mathrm{a}$ \\
Nero & $12,27 \mathrm{bc}$ & $463,50 \mathrm{bc}$ & $9,48 \mathrm{a}$ & $9,58 \mathrm{ab}$ & $2,49 \mathrm{ab}$ & $2,18 \mathrm{a}$ \\
Bônus no 2 & $13,15 \mathrm{a}$ & $693,25 \mathrm{a}$ & $10,20 \mathrm{a}$ & $10,48 \mathrm{a}$ & $2,80 \mathrm{a}$ & $2,09 \mathrm{a}$ \\
\hline
\end{tabular}

*-PMFC= Produção média de frutos comercializáveis $\left(\mathrm{Kg} / \mathrm{m}^{2}\right) ; \mathrm{PMF}=$ Peso médio dos frutos $(\mathrm{g})$; DML=Diâmetro médio longitudinal do fruto $(\mathrm{cm})$; DMT=Diâmetro médio transversal do fruto $(\mathrm{cm})$; EME=Espessura média do mesocarpo $(\mathrm{cm})$; EMEP=Espessura média do epicarpo (mm).

1- Médias seguidas da mesma letra dentro da coluna não diferem entre si pelo teste de tukey a $5 \%$ de probabilidade.

Tabela 2. Médias de Bix, pH, acidez titulável e coloração do mesocarpo e epicarpo. Jaboticabal, UNESP, 1996.

\begin{tabular}{|c|c|c|c|c|c|}
\hline \multirow{2}{*}{ Cultivares } & \multirow{2}{*}{ oBrix } & \multirow{2}{*}{$\mathrm{pH}$} & \multirow{2}{*}{$\begin{array}{l}\text { Acidez } \\
\text { titulável* }\end{array}$} & \multicolumn{2}{|c|}{ Coloração } \\
\hline & & & & Mesocarpo $^{2}$ & Epicarpo \\
\hline Sunrise & $11,67 \mathrm{a}$ & 6,92 a1 & $0,1320 a b$ & 2,6 & 2,0 \\
\hline Aragon & $8,52 \quad b$ & $6,65 \mathrm{a}$ & $0,1184 \quad b$ & 4,0 & 1,4 \\
\hline Hales Best Jumbo & $8,32 \mathrm{~b}$ & $6,92 \mathrm{a}$ & $0,1160 \quad b$ & 4,0 & 1,6 \\
\hline Nero & $12,27 \mathrm{a}$ & $7,15 \mathrm{a}$ & $0,1560 \mathrm{a}$ & 4,0 & 1,0 \\
\hline Bônus no 2 & $13,15 a$ & $7,10 \mathrm{a}$ & $0,1584 \mathrm{a}$ & 1,0 & 1,0 \\
\hline
\end{tabular}

*= valores expressos em gramas de ácido cítrico em $100 \mathrm{ml}$ da solução,

1) Médias seguidas da mesma letra dentro da coluna não diferem entre si pelo teste de tukey a $5 \%$ de probabilidade.

2) 1-verde; 2-verde-claro; 3-amarelo e 4-laranja;

3) 1-verde; e 2-amarelo,

350 a $700 \mathrm{~g}$, valores considerados baixos, segundo Siviero (1993), mas que ocorreram neste ensaio devido à incidência das doenças citadas anteriormente na fase final de desenvolvimento dos frutos, comprometendo, assim, suas dimensões.

Quanto ao diâmetro médio transversal e espessura média do mesocarpo, a cultivar Bônus $\mathrm{n}^{\circ} 2$ apresentou maiores valores, diferindo apenas de 'Aragon' e 'Hales Best Jumbo' (Tabela 1). O fruto ideal, segundo Costa \& Pinto (1977), deve ter mesocarpo espesso e cavidade interna pequena, pois frutos deste tipo resistem melhor ao transporte e têm maior durabilidade pós-colheita.

Com relação ao diâmetro médio longitudinal e a espessura média do epicarpo, o comportamento entre cultivares foi semelhante, não ocorrendo diferenças significativas (Tabela 1).

$\mathrm{Na}$ Tabela 2, observa-se que 'Sunrise', 'Nero' e 'Bônus no 2 ' não diferiram significativamente entre si, com relação ao teor de sólidos solúveis. Entre elas destacou-se 'Bônus $n^{\circ} 2^{2}$ ' com $11^{\circ}$ Brix. Os seus valores médios de ${ }^{\circ}$ Brix entre 11-13 conferem ótima qualidade para a comercialização, pois, para a exportação, os melões com Brix acima de $12^{\circ}$ são considerados "extra"; entre 9-12 ${ }^{\circ}$ Brix comercializáveis, e os que possuem ${ }^{\circ}$ Brix inferiores a estes valores não são comercializáveis (Siviero, 1993; Gorgatti Neto et al., 1994).

$\mathrm{Na}$ Tabela 2, observa-se que não houve diferenças significativas de $\mathrm{pH}$, estando os valores obtidos condizentes com os encontrados por Gonçalves et al. (1996). Quanto aos valores de acidez titulável, que diferiram significativamente entre as cultivares, também se encontraram no padrão considerado pelos mesmos autores.

Os dados da coloração do mesocarpo e do epicarpo de frutos das cinco cultivares de melão rendilhado estão apresentados na Tabela 2 .

A maior parte dos frutos apresentou intenso rendilhamento, característica normalmente desejável. Apenas alguns frutos provenientes de 'Hales Best Jumbo' se mostraram anormais. Essa anomalia, que conferiu menor rendilhamento, pode ter sido provocada pela ocorrência das doenças causadas pelos fungos anteriormente citados.

A cultivar Bônus $n^{\circ} 2$ destacou-se com relação à produção média $/ \mathrm{m}^{2}$, peso médio dos frutos, espessura da polpa e teores totais de sólidos solúveis ( ${ }^{\circ} \mathrm{Brix}$ ), características importantíssimas para a produção e comercialização dos frutos de meloeiro, podendo ser indicada para cultivo em casa de vegetação.

\section{AGRADECIMENTOS}

À Fundação de Amparo à Pesquisa (FAPESP) pela concessão da bolsa de mestrado.

\section{LITERATURA CITADA}

BRANDÃO FILHO, J.U.T.; VASCONSELOS, M.A.S.; A cultura do meloeiro. In: GOTO, R.; TIVELLI, S.W. Produção de hortaliças em ambiente protegido: condições subtropicais. São Paulo: Fundação Editora da UNESP, 1998, p.161-194. CHITARRA, M.I.F.; CHITARRA, A.B. Pós-Colheita de Frutos e Hortaliças: fisiologia e manuseio. Lavras: ESAL/FAEPE, 1990. 320 p. 
COSTA, C.P.; PINTO, C.A.B.P. Melhoramento de hortaliças. Piracicaba: ESALQ, Depto. de Genética, 1977. 319 p.

GONÇALVES, F.C.; MENEZES, J.B.; ALVES, R.E. Vida útil pós-colheita de melão 'Piel de sapo' armazenado em condição ambiente. Horticultura Brasileira, Brasília, v. 15, n. 1, p. 49-52, 1996. GORGATTI NETO, A.; GAYET, J.P.; BLEINROTH, E.W.; MATALHO, M.; GARCIA, E.E.C.; GARCIA, A.E.; ARDITO, E.F.G.; BORDIN, M.R. Melão para exportação: procedimentos de colheita e pós-colheita. Brasília:
EMBRAPA-SPI, 1994. p .37.

LESTER, G. Melon (Cucumis melo L.) fruit nutritional quality and health funcionality. HortTechnology, v. 7, n. 3, p. 222-7, 1997.

McCREIGHT, J.D.; NERSON, H.; GRUMET, R. Melon. In KALLOO, G.; BERGH, B.O. Genetic improvment of vegetable crops. p. 267-94, 1993. RAIJ, B. van; CANTARELLA, J.A.; QUAGGIO, R.; FURLANI, A.M.C., eds. Recomendações de adubação e calagem para o Estado de São Paulo. $2^{\text {a }}$ ed. Campinas: Instituto Agronômico \& Fundação IAC, 1996. p. 285.
RIZZO, A.A.N. Avaliação de caracteres agronômicos e qualitativos de cinco cultivares de melão rendilhado (Cucumis melo var. reticulatus Naud.) e da heterose de seus hibridos $F_{l}$. Jaboticabal, 1999. 61 p. (Dissertação mestrado), FCAV/ UNESP.

SIVIERO, P. La cultivazione del melone. Verona: Edizioni L'Informatore Agrario, 1993. p. 208

TRESSLER, D.K.; JOSLYN, M.A. Fruit and vegetable juice: processing technology. Westport, 1961. p.1028.

GUALBERTO, R.; RESENDE, F.V.; LOSASSO, P.H.L Produtividade e qualidade do melão rendilhado em ambiente protegido, em função do espaçamento e sistema de condução. Horticultura Brasileira, Brasília, v. 19, n. 3, p. 240-243, novembro 2.001.

\title{
Produtividade e qualidade do melão rendilhado em ambiente protegi- do, em função do espaçamento e sistema de condução.
}

\author{
Ronan Gualberto; Francisco Vilela Resende; Pedro Henrique L. Losasso \\ UNIMAR - FCA, C. Postal 554, 17.525-902 Marília-SP; Email: ronangual@uol.com.br
}

\section{RESUMO}

Visando avaliar a produtividade e qualidade do melão rendilhado em função do espaçamento e sistema de condução, foi realizado um ensaio em casa de vegetação com a cultivar Bônus $\mathrm{n}^{\circ} 2$, no período de agosto/98 a janeiro/99 em Marília (SP). Foram avaliados três espaçamentos entre plantas na fileira $(30,50$ e $70 \mathrm{~cm})$ e plantas conduzidas com uma haste e dois frutos $\left(\mathrm{S}_{1}\right)$, duas hastes com um fruto/haste $\left(\mathrm{S}_{2}\right)$, duas hastes com dois frutos/haste $\left(\mathrm{S}_{3}\right)$ e três hastes com um fruto/haste $\left(\mathrm{S}_{4}\right)$. Adotou-se um esquema de parcela subdividida com o espaçamento na parcela e sistema de condução na subparcela. O delineamento utilizado foi inteiramente casualizado com três repetições. Nos sistemas de condução $S_{1}$ e $S_{2}$ foram produzidos os frutos com maior diâmetro longitudinal $(11,46$ e 11,32 cm, respectivamente) e transversal (10,97 e $11,08 \mathrm{~cm}$, respectivamente) e, peso médio de fruto superior $(0,87 \mathrm{e} 0,89 \mathrm{~kg}$, respectivamente). Considerando a produtividade, o sistema $\mathrm{S}_{3}\left(7,44 \mathrm{~kg} / \mathrm{m}^{2}\right)$ foi superior aos demais, porém associado a um peso médio de fruto inferior. A maior concentração de sólidos solúveis atingiu $13,86^{\circ}$ Brix, observada no sistema de condução $\mathrm{S}_{2}$. O peso médio de fruto apresentou relação linear positiva com o aumento do espaçamento da cultura e a produtividade total de frutos reduziu gradativamente do menor para o maior espaçamento, seguindo uma tendência quadrática invertida. A condução da planta com duas hastes e um fruto/haste no espaçamento de $50 \mathrm{~cm}$ permitiu um melhor equilíbrio entre o peso médio de fruto adequado à comercialização e a maior produtividade possível.

\begin{abstract}
Greenhouse net melon fruits yield and yield quality in response to spacing and cultivation system.

An experiment was perfomed to evaluate yield and quality of net melon considering plants spacing and cultivation systems. The experiment was conducted in a greenhouse with cultivar Bonus $n^{\circ}$ 2, from August/98 to January/99 in Marilia, Brazil. Three plant spacing $(30,50$ and $70 \mathrm{~cm})$ and cultivation systems as one stem and two fruits $\left(\mathrm{S}_{1}\right)$, two stems and one fruit/stem $\left(\mathrm{S}_{2}\right)$, two stems with two fruits/stems $\left(\mathrm{S}_{3}\right)$ and three stems with one fruit/stem $\left(\mathrm{S}_{4}\right)$ were studied. A split plot design with spacing on plots was employed, and randomized blocks with three replicates. At $\mathrm{S}_{1}$ and $\mathrm{S}_{2}$ cultivation systems, fruits showed higher longitudinal diameter (11.46 and 11.32 $\mathrm{cm}$, respectively) and transverse (10.97 and $11.08 \mathrm{~cm}$, respectively), and higher mean fruits weight $(0.87$ and $0.89 \mathrm{~kg}$, respectively). Considering yield per area, $\mathrm{S}_{3}\left(7.44 \mathrm{Kg} / \mathrm{m}^{2}\right)$ presented the best performance, but with lesser mean fruit weight. The highest soluble solids content was obtained with $13.86^{\circ}$ Brix, at $\mathrm{S}_{2}$ cultivation. Mean fruit weight was positive linearly correlated to culture space increasing and total fruits yield was reduced from higher to smaller spacing, with inverted quadratic inclination. Plant cultivation with two stems and one fruit/stem at $50 \mathrm{~cm}$ spacing promoted better balance between mean fruit weight and marketing and higher yield by area.
\end{abstract}

Palavras-chave: Cucumis melo, casa de vegetação, frutos por haste.

Keywords: Cucumis melo, greenhouse, fruits per stem.

\section{(Aceito para publicação em 24 de outubro de 2.001)}

$\mathrm{O}$ melão rendilhado (Cucumis melo var. reticulatus Naud.) é uma espécie da família cucurbitaceae, pertencente ao grupo Reticulatus. $\mathrm{O}$ fruto possui superfície rendilhada, formato redondo-ovalado, aroma marcante, ${ }^{\circ} \mathrm{Brix} \pm 10^{\circ}$ e cor da polpa variando de verde-claro a salmão (Rizzo, 1999). No Brasil, o primeiro registro de cultivo para fins co- merciais deste grupo de melões, foi em 1986, pela Cooperativa Agrícola de Cotia, com sementes importadas do Japão.

O consumo de melão rendilhado está relacionado ao teor de sólidos solúveis, responsável pelo sabor, e ao aspecto visual, que o diferencia dos outros tipos de melões existentes no mercado. Sua qualidade nutricional, também, tem contribuído favoravelmente para seu consumo, pois sabe-se que estes melões são considerados pouco calóricos, além de serem boa fonte de sódio, potássio, vitamina C e beta-caroteno (Lester, 1997).

O melão rendilhado apresenta vantagens comerciais em relação aos outros melões, tais como preferência de mer- 